University of Nebraska - Lincoln

DigitalCommons@University of Nebraska - Lincoln

1995

\title{
Dephosphorylation of the Thylakoid Membrane Light-Harvesting Complex-II by a Stromal Protein Phosphatase
}

\author{
Mark E. Hammer \\ University of Nebraska-Lincoln \\ Gautam Sarath \\ University of Nebraska-Lincoln, Gautam.sarath@ars.usda.gov \\ John Markwell \\ University of Nebraska-Lincoln, jmarkwell2@unl.edu
}

Follow this and additional works at: https://digitalcommons.unl.edu/biochemistrysarath

Part of the Biochemistry, Biophysics, and Structural Biology Commons

Hammer, Mark E.; Sarath, Gautam; and Markwell, John, "Dephosphorylation of the Thylakoid Membrane Light-Harvesting Complex-II by a Stromal Protein Phosphatase" (1995). Gautam Sarath Publications. 19. https://digitalcommons.unl.edu/biochemistrysarath/19

This Article is brought to you for free and open access by the Biochemistry, Department of at DigitalCommons@University of Nebraska - Lincoln. It has been accepted for inclusion in Gautam Sarath Publications by an authorized administrator of DigitalCommons@University of Nebraska - Lincoln. 


\title{
Dephosphorylation of the thylakoid membrane light-harvesting complex-II by a stromal protein phosphatase
}

\author{
Mark E Hammer, ${ }^{1}$ Gautam Sarath, ${ }^{2}$ and John Markwell ${ }^{1}$ \\ ${ }^{1}$ Department of Biochemistry, University of Nebraska-Lincoln, Lincoln, NE 68588-0664, USA \\ ${ }^{2}$ Center for Biotechnology, University of Nebraska-Lincoln, Lincoln, NE 68588-0664, USA
}

\begin{abstract}
Light-harvesting complex-II (LHC-II) phosphatase activity has generally been examined in the intact thylakoid membrane. A recent report of peptide-phosphatase activity associated with the chloroplast stromal fraction (Hammer, M.E et al. (1995) Photosynth Res 44:107-115) has led to the question of whether this activity is capable of dephosphorylating membrane-bound LHC-II. To this end, heat-treated thylakoid membranes were examined as a potential LHC-II phosphatase substrate. Following incubation of the thylakoid membrane at 60 ${ }^{\circ} \mathrm{C}$ for $15 \mathrm{~min}$, the endogenous protein phosphatase and kinase activities were almost eliminated. Heat-inactivated phosphomembranes exhibited minimal dephosphorylation of the light harvesting complex-II. Peptidephosphatase activities isolated from the thylakoid and stromal fraction were able to dephosphorylate LHC-II in heat-inactivated phosphomembranes. The stromal phosphatase showed highest activity against LHC-II at $\mathrm{pH}$ 9. Dephosphorylation of the LHC-II by the stromal enzyme was not inhibited by molybdate, vanadate or tungstate ions, but was partially inhibited by EDTA and a synthetic phosphopeptide mimicking the LHC-II phosphorylation site. Thus, the previously identified stromal phosphatase does appear capable of dephosphorylating authentic LHC-II in vivo.
\end{abstract}

Keywords: chloroplast, LHC-II, protein phosphorylation

Abbreviations: CPP - chymotryptic phosphopeptides; LHC-II - light-harvesting complex of Photosystem II; MP - protein phosphatase fractionated from the thylakoid membrane; $\mathrm{P}_{2 \mathrm{Thr}}-$ synthetic phosphopeptide MRK-SAT(p)TKKVW; $\mathrm{SP}$ - protein phosphatase fractionated from the stromal compartment

\section{Introduction}

Chloroplast thylakoid membranes contain a number of proteins which are capable of being phosphorylated, with the most abundant being those associated with the LHC-II (Bennett 1977). The phosphorylation of thylakoid membrane proteins is accomplished through one or more protein kinases (Bennett 1991; Allen 1992). The LHC-II kinase is light regulated; phosphorylation of the LHC II is activated by reduction of plastoquinone, which is coincident with the State 1 to State 2 transition in photosynthetic energy distribution (Allen 1995).
Dephosphorylation of thylakoid proteins appears to be catalyzed by at least one phosphatase located in the thylakoid membrane (Bennett 1980). Isolation and characterization of a thylakoid protein phosphatase has been difficult due to its membrane location and the hydrophobic nature of the phosphoprotein substrates. Thylakoid membranes isolated from highly purified chloroplasts do not dephosphorylate general phosphatase substrates such as phosphorylase $\alpha$, histone, $\beta$-glycerolphosphate, or 4-methylumbelliferylphosphate (MacKintosh et al. 1991; Sun and Markwell 1992). Use of synthetic phosphopeptides analogous the LHC-II N-ter- 
minus phosphorylation site (Sun et al. 1993) or authentic phosphopeptides cleaved from the thylakoid proteins (Hammer et al. 1995) has recently allowed for the detection of solubilized protein phosphatase activity away from the membrane and the determination of initial rates of protein phosphatase activity. Synthetic phosphopeptides mimicking the LHC-II N-terminus have also been shown to inhibit the dephosphorylation rate of phosphoproteins in intact thylakoid membranes (Sun et al. 1993; Cheng et al. 1994).

Peptide substrates mimicking the LHC-II have allowed for the detection of a peptide phosphatase from the chloroplast stroma (Hammer et al. 1995). The stromal phosphatase and a detergent liberated membrane phosphatase were both inhibited by NaF and EDTA, but the stromal phosphatase had a more alkaline $\mathrm{pH}$ optimum and displayed much less inhibition by molybdate ions than did the membrane phosphatase. The total phosphopeptide phosphatase activity of the stromal phosphatase was similar to that of the membrane phosphatase, and thus could be a significant factor in thylakoid membrane dephosphorylation (Hammer et al. 1995).

To assess whether the stromal phosphatase could dephosphorylate authentic LHC-II apoproteins, we have developed an assay using heat-inactivated phosphomembranes as in vitro substrates for the protein phosphatase. Phosphorylated thylakoid membrane phosphoproteins, containing low endogenous protein phosphatase or kinase activity, were dephosphorylated by the stromal phosphatase, indicating that this enzyme is capable of LHC-II dephosphorylation in vivo.

\section{Materials and methods}

\section{Chloroplast isolation}

Pea (Pisum sativum L. cv. Alaska) plants were grown, and intact chloroplasts were isolated and purified on Percoll gradients as previously described (Sun et al. 1992). The intact chloroplasts were hypotonically lysed by resuspension in $25 \mathrm{mM}$ Na-Tricine ( $\mathrm{pH} 7.6), 5 \mathrm{mM}$ $\mathrm{MgSO}_{4}$ at a $\mathrm{Chl}$ concentration less than $0.2 \mathrm{mg} \mathrm{m} 1-1$, with the thylakoid membrane pellet and the stromal supernatant fractionated by centrifugation at $20,000 \mathrm{~g}$ for $10 \mathrm{~min}$. The membrane pellet and stromal fractions were stored in the dark for less than $1 \mathrm{~h}$ at $5^{\circ} \mathrm{C}$ prior to subsequent analysis.

Chl concentrations were measured in $80 \%$ acetone extracts (Arnon 1949).
Preparation of heat-inactivated phosphomembranes

Heat-inactivated phosphomembranes were prepared from isolated thylakoid membranes following incubation in $\left[\gamma^{-}{ }^{32} \mathrm{P}\right] \mathrm{ATP}$ to label the endogenous phosphoproteins. Membranes containing $10 \mathrm{mg} \mathrm{Chl}$ were resuspended in $10 \mathrm{ml}$ total volume containing the following: $25 \mathrm{mM}$ Na-Tricine (pH 7.6), $5 \mathrm{mM} \mathrm{MgSO}_{4}, 20 \mathrm{mM} \mathrm{NaF}$, $200 \mu \mathrm{M}$ unlabeled ATP, and $1 \mathrm{mCi}\left[\gamma^{-32} \mathrm{P}\right.$ ]ATP $(7000 \mathrm{Ci}$ $\mathrm{mmo1}^{-1}$, ICN Biomedicals, Inc.). The mixture was incubated in the light $\left(500 / \mu \mathrm{mol}\right.$ photons $\mathrm{m}^{-2} \mathrm{~s}^{-1}$ in the 400 to $700 \mathrm{~nm}$ range) at $30^{\circ} \mathrm{C}$ for $15 \mathrm{~min}$. Following the incubation, the mixture containing the phosphorylated membranes was made to $20 \mathrm{mM}$ EDTA and placed in a $60{ }^{\circ} \mathrm{C}$ water bath for $30 \mathrm{~min}$. Membranes were then pelleted by centrifugation at 20,000 $\mathrm{g}$ for $10 \mathrm{~min}$, suspended in $25 \mathrm{mM} \mathrm{Na-Tricine} \mathrm{(} \mathrm{pH} \mathrm{7.6),} 5 \mathrm{mM} \mathrm{MgSO}_{4^{\prime}}$ and pelleted again as above. The final membrane pellet was suspended in $3 \mathrm{ml} 100 \mathrm{mM}$ Tris $\mathrm{C} 1$ (pH 8.5), $5 \mathrm{mM} \mathrm{Mg}$ acetate, $5 \mathrm{mM}$ dithiothreitol and 20\% glycerol. Heat-inactivated phosphomembranes were stored at $-80^{\circ} \mathrm{C}$ until use.

\section{Protein phosphatase fractionation}

The Brij 35-liberated membrane CPP-phosphatase, or the stromal CPP-phosphatase, were fractionated using Sephacryl S-200 chromatography as previously described (Hammer et al. 1995). Phosphatase containing fractions were dialyzed into $5 \mathrm{mM}$ Tris- $\mathrm{Cl}$ ( $\mathrm{pH}$ 8.5), 5 $\mathrm{mM} \mathrm{Mg}$ acetate, $1 \mathrm{mM}$ DTT prior to assay with heat-inactivated phosphomembranes.

\section{Assay of exogenous phosphatases using heat-inactivated phosphomembranes}

Heat-inactivated, labeled phosphomembranes were thawed, centrifuged at 15,000 g, and the pellet resuspended at $2 \mathrm{mg} \mathrm{Chl} \mathrm{ml}^{-1}$ with a buffer containing 100 $\mathrm{mM}$ Tris $\mathrm{C} 1$ ( $\mathrm{pH} 8.5), 5 \mathrm{mM} \mathrm{Mg}$ acetate, $5 \mathrm{mM}$ dithiothreitol (for the stromal phosphatase) or with a buffer containing $100 \mathrm{mM}$ HEPES (pH 7.2), $5 \mathrm{mM} \mathrm{Mg}$ acetate, $5 \mathrm{mM}$ dithiothreitol (for the membrane phosphatase). Phosphatase fractions isolated from the membrane or stroma containing ca. 5 pmol min ${ }^{-1} \mathrm{ml}^{-1} \mathrm{CPP}$-phosphatase activity were mixed with an equal volume of heatinactivated phosphomembranes and incubated at 30 ${ }^{\circ} \mathrm{C}$ for various lengths of time. Reactions were stopped with the addition of an equal volume of denaturing 
sample buffer (125 mM Tris-Cl, pH 6.8, 10\% SDS, 5\% $\beta$-mercaptoethanol, 25\% glycerol, $0.05 \%$ bromophenol blue), heated at $90{ }^{\circ} \mathrm{C}$ for $15 \mathrm{~min}$, then separated using discontinuous SDS-PAGE (Laemmli 1970). Gels were stained with Coomassie brilliant blue, dried, and the ${ }^{32} \mathrm{P}$ imaged using a Phosphorimager SF (Molecular Dynamics, Sunnyvale, CA, USA). The LHC-II band from the control reactions generally contained ca. $6000 \mathrm{dpm}$ radioactivity.

For the measurement of $\mathrm{pH}$ optima, heat-inactivated phosphomembranes and the stromal phosphatase were incubated in $250 \mathrm{mM}$ Tris-Cl, adjusted to $\mathrm{pH} 7$ through 9, containing $5 \mathrm{mM}$ dithiothreitol, and $5 \mathrm{mM}$ magnesium acetate.

Preparation of phosphopeptides and peptide phosphatase assay

To initially assay endogenous phosphatase activity, chymotryptic phosphopeptides (CPP) were used as substrates. The CPP were prepared from isolated thylakoid membranes as previously described (Hammer et al. 1995). Briefly, thylakoid membranes were incubated with $\left[\gamma^{-32} \mathrm{P}\right] \mathrm{ATP}$ to label the endogenous phosphoproteins. The membranes were then incubated with chymotrypsin to liberate phosphorylated peptides. Peptides were fractionated using $\mathrm{C}_{18}$-silica chromatography (Hammer et al. 1995).

The synthetic peptide $\mathrm{P}_{2 \mathrm{Thr}}$ (MRKSATTKKVW) was phosphorylated by incubation with isolated thylakoid membranes as previously described (Sun et al. 1993). Phosphorylation of this peptide by the endogenous thylakoid protein kinase activity results in a specific phosphorylation of $\mathrm{Thr}^{6}$ (Michel and Bennett 1989).

The assay used to measure CPP-dephosphorylation was previously described (Hammer et al. 1995). Following incubation of the CPP with the enzyme fraction, ${ }^{32} \mathrm{P}_{\mathrm{i}}$ released was assayed by phase partitioning (Shacter 1984) and Cerenkov counting. The determination of phosphopeptide concentration and $\mathrm{P}_{\mathrm{i}}$ released during the assay were based on the ${ }^{32} \mathrm{P}$ specific radioactivity in the labeling reaction.

\section{Results and discussion}

\section{Heat-inactivated thylakoid phosphomembranes}

To develop a phosphomembrane substrate for the chloroplast protein phosphatase that did not contain endogenous phosphatase activity, it was first necessary

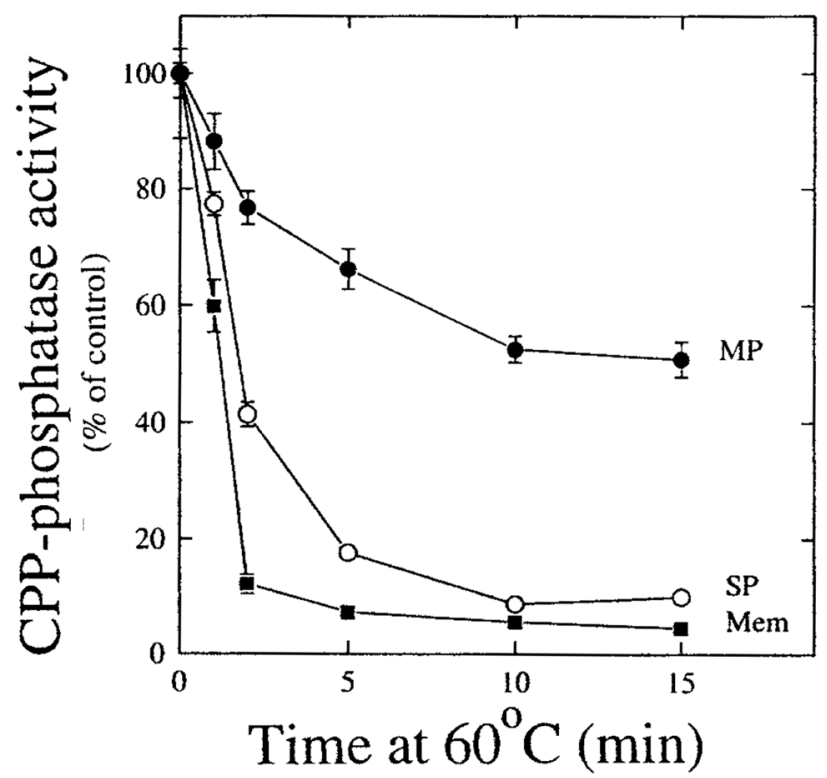

Figure 1. The effect of heating at $60{ }^{\circ} \mathrm{C}$ on phosphopeptidephosphatase activity in pea chloroplast fractions. Activity was assayed from isolated thylakoid membranes (Mem), detergentliberated, and Sephacryl-S-200 fractionated membrane phosphatase (MP), or Sephacryl-S-200 fractionated stromal phosphatase (SP). Following incubation at $60 \mathrm{o} \mathrm{C}$ for the indicated lengths of time, fractions were cooled to $30{ }^{\circ} \mathrm{C}$ and assayed for protein phosphatase activity using chymotryptic phosphopeptides (CPP) as a substrate. Specific activities at 100\% for Mem, 8.7 pmol $\mathrm{P}_{\mathrm{i}}$ released $\mathrm{min}^{-1} \mathrm{mg}^{-1}$ protein; $\mathrm{MP}, 23.7 \mathrm{pmol} \mathrm{min}^{-1}$

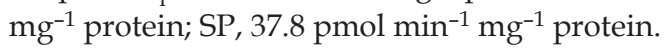

to examine conditions that would lead to phosphatase inactivation while largely maintaining membrane integrity. When thylakoid membranes were heated at various temperatures for $15 \mathrm{~min}$, cooled to $30^{\circ} \mathrm{C}$, and assayed for CPP-phosphatase activity, the threshold temperature causing a significant decrease in activity of the thylakoid membranes was $60^{\circ} \mathrm{C}$. Incubation of membranes at this temperature caused a rapid loss of CPP-phosphatase activity to less than $5 \%$ of pre-incubation levels within $15 \mathrm{~min}$ (Figure 1). The $60{ }^{\circ} \mathrm{C}$ temperature treatment did not, however, cause any visible aggregation of the thylakoid membranes. To examine whether heat inactivation of phosphatase activity was similar when the enzyme was removed from the thylakoid membranes, detergent solubilized membrane phosphatase and the stromal phosphatase were also tested. Surprisingly, when removed from the membrane prior to the heating treatment, the membrane phosphatase did not show similar inactivation of CPP-phosphatase activity, and was inactivated less than $50 \%$ after a 15 min incubation (Figure 1). However, CPP-phosphatase activity of the stromal enzyme was reduced to $9 \%$ of pre-incubation levels af- 


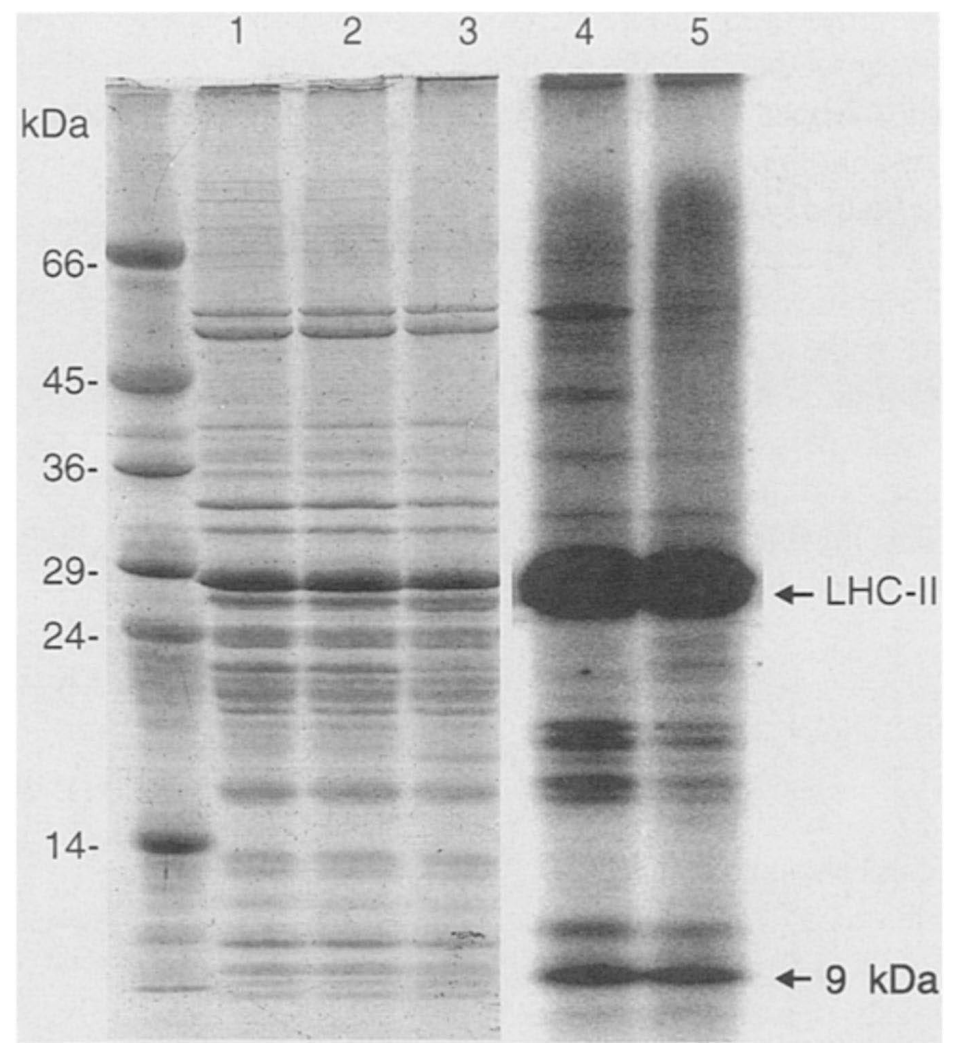

Figure 2. Effects of phosphorylation and $60^{\circ} \mathrm{C}$ temperaua 4 treatment on protein profiles (lanes $\left.1-3\right)$ and ${ }^{32} \mathrm{P}$ incorporation (lanes 4--5) following SDS-PAGE. Thylakoid membranes (lane 1) were phosphorylated with the endogenous kinase in the presence of $\left.\gamma^{-32} \mathrm{P}\right]$ ATP (lane 2) then incubated at $60{ }^{\circ} \mathrm{C}$ for $30 \mathrm{~min}$ (lane 3). Lanes 4 and 5 are a phosphorimage of lanes 2 and 3 , respectively. The position of the LHC-II proteins and the $9 \mathrm{kDa}$ protein are shown with arrows.

ter $10 \mathrm{~min}$ at $60^{\circ} \mathrm{C}$ (Figure 1). Detergent liberation of the membrane phosphatase may have caused some conformational or structural changes to the enzyme that made it less sensitive to heat denaturation. Heat-treated membranes were also examined for endogenous protein kinase activity. Following incubation at $60^{\circ} \mathrm{C}$ for $30 \mathrm{~min}$, thylakoid membrane proteins were not phosphorylated under conditions optimal for kinase activity (data not shown).

Once it was established that the protein phosphatase activity endogenous to the thylakoid membrane could be inactivated over $95 \%$ following incubation at $60{ }^{\circ} \mathrm{C}$, the effects of heating on the phosphoproteins were examined. When the thylakoid membranes (Figure 2, lane 1) were phosphorylated by the endogenous kinase by adding $\left[\mathrm{\gamma}^{-32} \mathrm{P}\right] \mathrm{ATP}$ (Figure 2, lane 2) and then incubated at $60^{\circ} \mathrm{C}$ (Fig 2, lane 3), there was little change in the profile of Coomassie brilliant blue-stained proteins separated using SDS-PAGE. The addition of $\left[\gamma^{-32} \mathrm{P}\right]$ ATP to unheated thylakoid membranes caused a number of thylakoid membranes to become phosphorylated as visualized using phosphorimage analysis (Figure 2, lane 4). At least eleven proteins were noticeably phosphorylated, with the LHC-II apoproteins at 26 and $27 \mathrm{kDa}$, and the $9 \mathrm{kDa}$ protein exhibiting the greatest amount of ${ }^{32} \mathrm{P}$ incorporation. A similar pattern of thylakoid membrane phosphorylation as been shown elsewhere (Markwell et al. 1984; Silverstein et al. 1993; Cheng et al. 1994). Heat treatment of the thylakoid membranes, in the presence of NaF and EDTA, did not cause a significant loss of ${ }^{32} \mathrm{P}$ from the LHC-II and the $9 \mathrm{kDa}$ protein, while some minor thylakoid phosphoproteins did show a loss of radioactive label (Figure 2, lane 5). The dephosphorylation of some of these proteins may be due to an initial stimulation of the membrane phosphatase or an increase in membrane fluidity during heating. Since the LHC-II remained highly labeled following heat treatment, the validity of heat-inactivated thylakoid phosphomembranes as a substrate for exogenous LHC-II phosphatases was explored. 

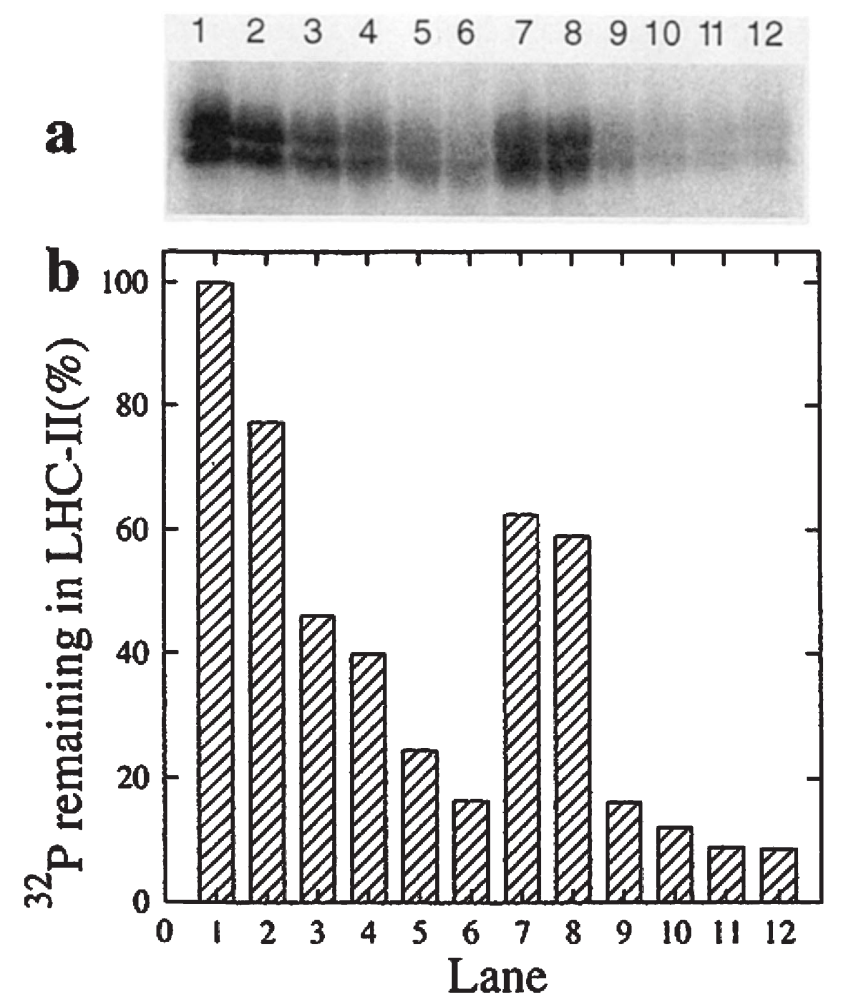

Figure 3. Dephosphorylation of the LHC-II in heat-inactivated thylakoid phosphomembranes following incubation with the membrane phosphatase (MP, lanes 1-6) or stromal phosphatase (SP, lanes 7-12). The phosphorimage of the SDS-PAGE separation (a) was integrated to measure ${ }^{32} \mathrm{P}$ labeling of LHCII (b). Lanes 1 and 7 are at the start of exogenous phosphatase addition; lanes 2 and 8 are control reactions incubated for 120 minutes in the absence of exogenous enzyme. Times of incubation with the exogenous phosphatase were 15 min (lanes 3 and 9), 30 rain (lanes 4 and 10), 60 min (lanes 5 and 11) and $120 \mathrm{~min}$ (lanes 6 and 12).

\section{Heat-inactivated phosphomembranes as substrate for exogenous LHC-H phosphatases}

The dephosphorylation of heat-inactivated phosphomembranes was examined using protein phosphatase activities associated with the stromal compartment (SP) or liberated from the thylakoid membranes by detergent treatment (MP). These phosphatases originated from Percoll-gradient purified pea chloroplasts. The phosphatases were further fractionated using Sephacryl S-200 chromatography. The MP and SP have similar elution profiles from gel permeation chromatography, but have been found to differ in their $\mathrm{pH}$ optima and response to molybdate ions (Hammer et al. 1995).

When MP or SP, having an equivalent CPP-phosphatase activity, were incubated with heat-inactivated phosphomembranes for various lengths of time, de- phosphorylation of the LHC-II was apparent (Figure $3)$. In contrast, there was limited dephosphorylation of the LHC-II after $120 \mathrm{~min}$. incubation at $30^{\circ} \mathrm{C}$ in the absence of exogenous phosphatase (Figure 3, lane 2 and 8). Following 120 minutes of incubation, the MP dephosphorylated $83 \%$ of LHC-II associated ${ }^{32} \mathrm{P}$ while the SP dephosphorylated $86 \%$ of the LHC-II label, compared to the zero-time value for each enzyme fraction. Even though the Coomassie brilliant blue-stained gel indicated that all the lanes had similar amounts of LHC-II protein, there was a difference in LHC-II labeling intensities at time zero of the experiment (Figure $3 b$, lanes 1 and 7). This difference may be due to a more rapid dephosphorylation by the SP before the reaction could be stopped with the addition of denaturing sample buffer.

With longer phosphorimage exposures, the $9 \mathrm{kDa}$ phosphoprotein showed a similar pattern of dephosphorylation as compared to that of the LHC-II (data not shown). Dephosphorylation was observed in other thylakoid membrane phosphoproteins but was difficult to quantify due to their diminished isotope labeling following the heat treatment (Figure 2, lane 5).

Validation of heat-inactivated thylakoid phosphomembranes as substrates for chloroplastic protein phosphatase, and demonstration that the SP will dephosphorylate thylakoid membrane associated LHC-II, allowed for the further characterization of this stromal activity.

\section{Characterization of stromal LHC-II-phosphatase activity}

Stromal LHC-II-phosphatase activity was characterized using heat-inactivated phosphomembranes as substrate. Following the dephosphorylation reaction, aliquots were separated on SDS-PAGE, visualized with the phosphorimager, and the ${ }^{32} \mathrm{P}$ associated with the LHCII quantified.

Significant SP-catalyzed dephosphorylation of LHCII was observed at $\mathrm{pH}$ values from 7.0 to 9.0, with a dephosphorylation optimum at $\mathrm{pH}$ 9. This was consistent with the CPP-phosphatase activity of the SP in response to assay $\mathrm{pH}$ (Hammer et al. 1995).

As previously reported for SP CPP-phosphatase activity (Hammer et al. 1995), dephosphorylation of LHC-II by SP was not inhibited by $10 \mathrm{mM}$ molybdate ions but was partially inhibited by $10 \mathrm{mM}$ EDTA. Additionally, $10 \mathrm{mM}$ vanadate or tungstate ions were also found not to inhibit LHC-II dephosphorylation (data not shown). 


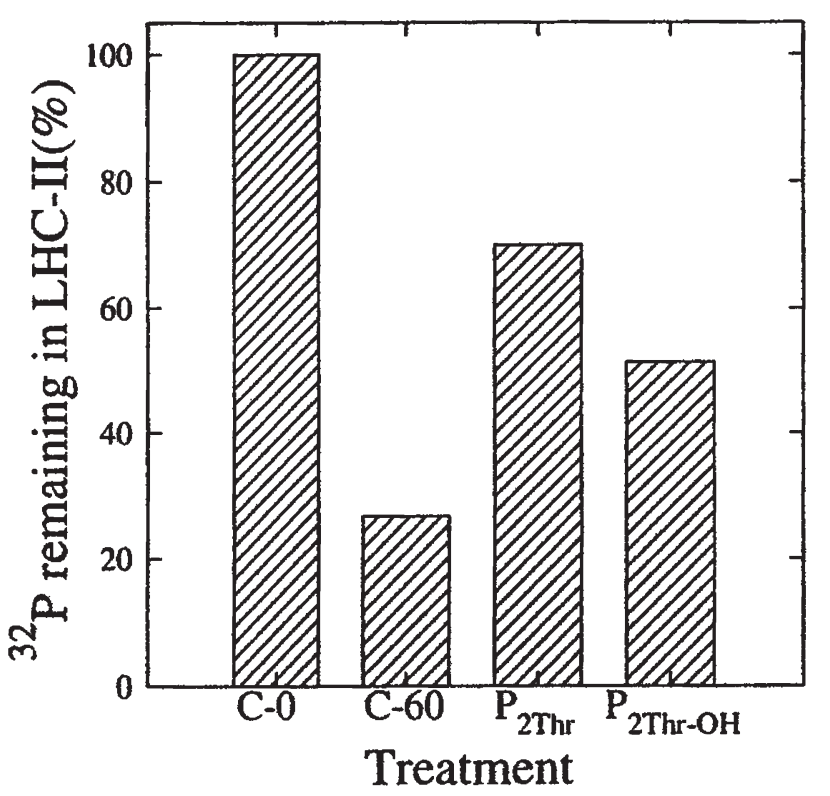

Figure 4. Effect of synthetic peptides on dephosphorylation of phospho-LHC-II by the stromal phosphatase fraction. Heat-inactivated thylakoid phosphomembranes were incubated with the stromal phosphatase for 0 or $60 \mathrm{~min}$ (C-0 or C-60, respectively) or incubated with the stromal phosphatase for $60 \mathrm{~min}$ in the presence of $7 \mu \mathrm{M}$ phosphorylated $\left(\mathrm{P}_{2 \mathrm{Thr}}\right)$ or unphosphorylated $\left(\mathrm{P}_{2 \mathrm{Thr}-\mathrm{OH}}\right)$ peptides. Following incubation, samples were separated on SDS-PAGE, and the amount of ${ }^{32} \mathrm{P}$ labeling in LHC-II was measured by phosphorimaging.

To provide further evidence for the specificity of the stromal phosphatase, dephosphorylation of the heat-inactivated phosphomembranes was examined with the addition of synthetic phosphopeptides. The dephosphorylation of LHC-II by SP was inhibited by the phosphorylated synthetic peptide $\mathrm{P}_{2 \mathrm{Th}}$, an analog of the LHC-II phosphorylation site (Figure 4). Following a 60 minute reaction time, the control SP reaction dephosphorylated LHC-II by 73\%, while with the addition of $7 \mu \mathrm{M} \mathrm{P} \mathrm{P}_{2 \mathrm{Thr}}$ the LHC-II was dephosphorylated only by $30 \%$. The addition of the non-phosphorylated peptide $\left(\mathrm{P}_{2 \mathrm{Thr}-\mathrm{OH}}\right)$ did not cause the same extent of inhibition of dephosphorylation as the phosphorylated peptide (Figure 4). Similarly, in intact membranes, the endogenous membrane protein phosphatase is inhibited by the addition of a phosphopeptide analogues of the LHC-II N-terminus (Sun et al. 1993; Cheng et al. 1994).

\section{Conclusions}

Heat-inactivated phosphomembranes appear to be a suitable substrate with which to assay the ability of enzymes to dephosphorylate authentic LHC-II. The use of such substrate, without significant endogenous protein phosphatase activity, is an important step to begin the isolation of LHC-II phosphatases from the thylakoid membrane. The use of such substrate has also allowed for the examination of potential LHC-II phosphatases not associated with the thylakoid membrane. The stromal fraction of isolated chloroplasts contains a protein phosphatase activity that is active on LHC-II in the membrane, and could be capable of LHC-II dephosphorylation in vivo. The total LHC-II peptide phosphatase activity in the stroma has been shown to be of equal magnitude to that of the thylakoid membrane (Hammer et al. 1995), indicating that the stromal activity is a significant component in the chloroplast. With the model of LHC-II phosphorylation and dephosphorylation currently proposed (Allen 1992), the LHC-II migrates from granal thylakoids to stromal-exposed thylakoids following phosphorylation (State 1 to State 2). A membranebound LHC-II phosphatase catalyzes the dephosphorylation which causes the LHC-II to migrate back to the granal thylakoids (State 2 to State 1). Would a stromal LHC-II phosphatase be additionally needed to provide more dynamic access to phosphorylated LHC-II? The exact role of a potential stromal LHC-II phosphatase is not known, but this activity should be considered in further investigations of LHC-II phosphorylation and dephosphorylation.

\section{Acknowledgments}

This work was supported by the National Science Foundation (grant \#MCB-9303871 to J.M. and G.S.) and the University of Nebraska-Lincoln Center for Biotechnology. This is paper No. 11158, Journal series, from the Nebraska Agricultural Research Division. We are grateful to Shrinivas Bishu for help with some of the experiments.

\section{References}

Allen JF (1992) Protein phosphorylation in regulation of photosynthesis. Biochim Biophys Acta 1098:275-335

Allen JF (1995) Thylakoid protein phosphorylation, state 1state 2 transitions, and photosystem stoichiometry adjustment: Redox control at multiple levels of gene expression. Physiol Plant 93: 196-205

Amon DI (1949) Copper enzymes in isolated chloroplasts. Plant Physiol 24:1-15 
Bennett J (1977) Phosphorylation of chloroplast membrane polypeptides. Nature 269:344-346

Bennett J (1980) Chloroplast phosphoproteins: evidence for a thylakoid-bound phosphoprotein phosphatase. Eur J Biochem 104:85-89

Bennett J (1991) Protein phosphorylation in green plant chloroplasts. Annu Rev Plant Physiol Plant Mol Biol 42:281-311

Cheng L, Spangfort MD, and Allen JF (1994) Substrate specificity and kinetics of thylakoid phosphoprotein phosphatase reactions. Biochim Biophys Acta 1188:151-157

Hammer MF, Sarath G, Osterman JC, and Markwell J (1995) Assessing modulation of stromal and thylakoid light-harvesting complex-II phosphatase activities with phosphopeptide substrates. Photosynth Res 44:107-115

Laemmli UK (1970) Cleavage of structural proteins during the assembly of the head of bacteriophage T4. Nature 227:680-685

MacKintosh C, Coggins J, and Cohen P (1991) Plant protein phosphatases: subcellular distribution, detection of protein phosphatase 2C and identification of protein phosphatase $2 \mathrm{~A}$ as the major quinate dehydrogenase phosphatase. Biochem J 273: 733-738
Markwell JP, Baker NR, Bradbury M, and Thomber JP (1984) Use of zinc ions to study thylakoid protein phosphorylation and the state 1-state 2 transitions in vitro. Plant Physiol 74:348-354

Michel H and Bennett J (1989) Use of synthetic peptides to study the substrate specificity of a thylakoid protein kinase. FEBS Lett 254:165-170

Shacter E (1984) Organic extraction of $\mathrm{P}_{\mathrm{i}}$ with isobutanol/toluene. Anal Biochem 138:416-420

Silverstein T, Cheng L, and Allen JF (1993) Chloroplast thylakoid protein phosphatase reactions are redox-independent and kinetically heterogeneous. FEBS Lett 334:101-105

Sun G and Markwell J (1992) Lack of types 1 and 2A protein serine $(\mathrm{P}) /$ threonine $(\mathrm{P})$ phosphatase activities in chloroplasts. Plant Physiol 100:620-624

Sun G, Sarath G, and Markwell J (1993) Phosphopeptides as substrates for thylakoid protein phosphatase activity. Arch Biochem Biophys 304:490-495 